'llu. Revista de Ciencias de las Religiones

ISSN: $1135-4712$

http://dx.doi.org/10.5209/ILUR.57425

\title{
Eva y la triple T en las tradiciones judía e islámica
}

Khaoula $\operatorname{Trad}^{1}$

Recibido: 27 de febrero de 2017 / Aceptado: 16 de mayo de 2017

Resumen. En este artículo se pretende llevar a cabo un estudio comparativo del momento decisivo de los relatos bíblico y coránico de la vida de Eva que es la violación del pacto hecho con el Creador, el de no acercarse ni comer del árbol prohibido, con el fin de establecer elementos estructurales comunes y distintos. La violación de la orden divina no nació de la nada, tenía sus causas y consecuencias. La Triple $T$ designa las tres etapas de dicha violación. En la primera que es la tentación, veremos la incitación e iniciación al hecho transgresor. A continuación, en la transgresión, explicaremos cómo fue la desobediencia. Por último, viene la tragedia que engloba los resultados y las consecuencias.

Palabras clave: Eva; Adán; judaísmo; islam; tradición; Iblīs; serpiente; paraíso.

\section{[en] Eve and the triple $\mathrm{T}$ in the Jewish and Islamic traditions}

\begin{abstract}
This paper offers a comparative study of the decisive moment in the biblical and quranic story of Eve, generally perceived as having been the violation of the covenant made with the Creator. According to it, Adam and Eve were forbidden to approach the tree or to eat from its fruit, a fact that is generally perceived as having been meant to establish common and different structural elements. The violation of the divine order did not come out of nowhere; it had its causes and consequences. The triple $T$ divides the violation into three stages. In the first one, which is the temptation, we encounter the incitement and the initiation to the transgressor incident. Then, in the transgression, we find out, how the disobedience happened. Finally, comes the tragedy, which includes the results and the consequences.

Keywords: Eve; Adam; Judaism; Islam; tradition; Iblīs; snake; paradise.
\end{abstract}

Sumario. 1. Introducción. 2. Tentación y transgresión. 3. La tragedia. 4. Cuando el final es el comienzo. 5. La muerte de Eva. 6. Conclusiones. 7. Bibliografía. 7.1 Fuentes. 7.2. Literatura secundaria.

Cómo citar: Trad, K. (2017), Eva y la triple T en las tradiciones judía e islámica, en 'Ilu. Revista de Ciencias de las Religiones 22, 475-492.

\section{Introducción}

Junto a Adán, su pareja Eva formó el núcleo principal de la vida humana, contribuyendo a la continuidad y al florecimiento del género humano. Tanto el Judaísmo como el Islam trataron el tema de la madre de la Humanidad. Obviamente, las diferencias entre canon y doctrinas hacen que cada tradición construya la historia

\footnotetext{
1 Universidad de Hamburgo (Alemania).

E-mail: khaoula.trad@uni-hamburg.de
} 
con una perspectiva particular, entienda e interprete sus significantes teológicos ${ }^{2}$ tomando, por tanto, lo que se adecue a sus pensamientos y creencias. Las tradiciones nunca estancan, sino que van intercambiando entre sí, modificando y modelándose según la sociedad y la religión que las adapta. Por lo cual, entre las tradiciones judía e islámica existen puntos en común y otros totalmente diferentes.

\section{Tentación y transgresión}

El tercer capítulo del Génesis presenta sus dos protagonistas por excelencia: la mujer y la serpiente que es la bestia más asusta en todo el Edén: pero la serpiente era el más asusto de los animales del campo que Yahvé Elohim había producido. (Gn3: 1). Este animal es una criatura de Dios y Adán le dio su nombre (Gn2:20). El término

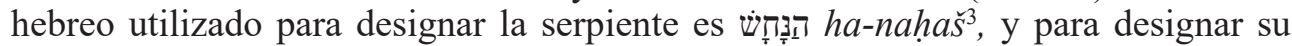
adjetivo calificativo se emplea asusto עָרום 'arum. La misma palabra se utiliza en el

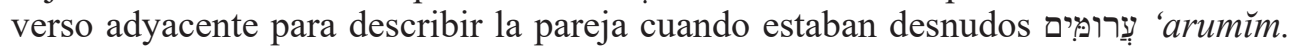
Para entender más esta paranomasia hay que volver un poco atrás en la narración bíblica. En efecto, el relato dice que los dos estaban desnudos, el hombre y la mujer, pero no sentían vergüenza. (Gn2: 25). Estaban los dos en una armonía perfecta y aún no existía el mal; esta situación ideal habría podido ser eterna si no hubiese intervenido algo o alguien. De aquí, entendemos la causa de la colocación inmediata de la serpiente en el próximo verso del nuevo capítulo del Génesis. Este animal es quien pondrá fin a esta situación. Este juego de palabras entre los dos adjetivos subraya el nacimiento de la relación entre el ser humano y la serpiente. El juego de palabras engendra también un juego de sonidos, que une, en la mente del lector del texto, la astucia con la desnudez, pero «como en un palimpsesto, los significados barrados permanecen justo debajo de la superficie ${ }^{4} . »$

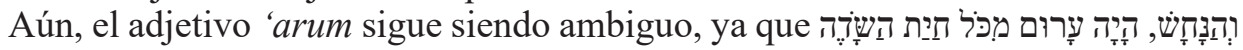
se puede entender positivamente como «la serpiente era la más sabia, la más prudente», o negativamente como «era la más asusta y la más maliciosa». Es evidente la elección de la serpiente ${ }^{5}$ entre todos los animales por su valor simbólico. En las culturas del Antiguo Oriente la serpiente era símbolo del poder, del caos, de la fertilidad, del mal y de la sexualidad ${ }^{6}$. Pero en el pensamiento post-bíblico se identificó con el diablo. El pensamiento rabínico pintó la serpiente como la más maldita de todas las bestias. Tenía la apariencia de un camello y era muy poderosa:

Se enseñó en nombre de R. Meir: Conforme a la grandeza de la serpiente fue su caída: el animal más asusto de todos, el más maldito de todos [...] R. Hosayah el Viejo dijo: se mantenía erguido como una caña, y tenía patas. R. Yirmeah ben

\footnotetext{
Kvam, 1999, 3.

Corresponde al árabe hanaš y al sumerio šahan. Este último es el nombre de un Dios que significa serpiente; se identifica con Ningishzida, que era el Dios mesopotámico de la fecundidad, representado con una cabeza de serpiente en cada hombro. Era el señor del árbol de la vida. Esto nos lleva a pensar en la relación que existe entre la serpiente y el árbol de la vida.

4 Kimelman, 1999, 256-57.

5 «La tradición yahvista elige a la serpiente como portavoz de la seducción en clara polémica contra los cultos cananeos de la fertilidad, en los que dicho reptil juega un papel simbólico...» Cfr. Ruiz Martorell, 1998, 30-31.

6 Aronson, 1992, 148-49.
} 
Elazar dijo: era un escéptico. R. Simeón ben Elazar dijo: Era como un camello. De un gran bien quedó privado el mundo, pues de no haber sucedido así, el hombre se habría servido de él para enviar sus mercancías, confiado en que iría y volvería. $(\mathrm{Gn} R \mathrm{R} 19,1)$

Según Filón, la serpiente es el placer que une la sensibilidad y la inteligencia: «El motivo por el que compara al placer con una serpiente es el siguiente: el movimiento del placer es como él de la serpiente; tortuoso y variable.» (Inter. II, XVIII, 74). Flavio Josefo afirma que la serpiente tenía envidia y estaba tan celosa de la vida paradisiaca que llevaba Eva con su marido, que por eso, empezó a pensar y planear cómo acabar con esto: «La serpiente que vivía con Adán y su mujer, les envidiaba que fueran felices viviendo en obediencia de los mandamientos de Dios.» (Ant. L.I, C.I, 2). Viene este midrash para confirmar la idea de Flavio Josefo:

R. Yehudá ben Tema dice: Estaba el primer hombre recostado en el Paraíso y los ángeles del Servicio permanecían de pie ante él: le asaban la carne, le filtraban el vino y venían a servirle. Fue la serpiente y le vio, y advirtiendo el honor que le dispensaban, se llenó de celo. [...] En aquellos tiempos era el aspecto de la serpiente como el de una especie de camello. (MidGad Gn. 3:1)

En el libro de los Jubileos, la serpiente aparece en el séptimo año de la creación, justo el día diecisiete del segundo mes: «Al final de los siete años que pasó allí, siete años exactos, el diecisiete del segundo mes, llegó la serpiente» (C. III, 17). El texto bíblico no añade más detalles sobre la serpiente salvo uno que es muy importante: la serpiente está dotada del habla ${ }^{7}$. También en esta escena Eva habló por la primera vez. Tampoco el relato nos explica los motivos por qué la serpiente se dirigió hacia la mujer y no hacia el hombre ${ }^{8}$. En la tradición judía se entiende que la serpiente supo tentar a la mujer de acuerdo a su condición natural: su debilidad, lo que la llevó a aceptar la conversación:

La serpiente se hizo el siguiente razonamiento: «Si le hablo al hombre, sé que no me va a hacer caso, pues resulta siempre difícil sacar a un hombre de sus casillas. La hablaré, pues, a la mujer, cuyo juicio es más ligero, pues sé que ella me va a hacer caso: que las mujeres son dadas a escuchar a todas las criaturas, como está dicho: embaucadora y no sabe nada (Prov 9, 13).» (PRE 13,3)

La serpiente fue quien inició el diálogo:

...Y dijo a la mujer: "¿Con qué Elohim ha dicho no habéis de comer de ningún árbol del vergel?» Y contestó la mujer a la serpiente: "del fruto de los árboles del vergel podemos comer, pero respecto al fruto del árbol que está en lo interior

\footnotetext{
En la Biblia hay otro caso de un animal que habla: el burro de Balaam.

¿Sería porque la mujer es más curiosa, más débil, no es de confiar, o tonta? ¿O porque la serpiente es un símbolo de la vida y la fertilidad, es lógico que hable con la mujer al saber también que ella encarna la vida y la fecundidad? Respecto a esto, los rabinos se preguntaron sobre el lugar donde estaba Adán mientras la serpiente hablaba con su mujer: «Abba Jalfon bar Qoriah dijo: se había dedicado a las funciones naturales y estaba dormido. Los maestros decían: Dios le había tomado y llevado alrededor de todo el mundo, diciéndole: Aquí hay un lugar apropiado para plantar, aquí un lugar adecuado para sembrar.» (Gn R 19, 3).
} 
del vergel ha dicho Elohim: no comáis de él ni lo toquéis, para que no muráis.». La serpiente dijo a la mujer: «no moriréis por supuesto: es que Elohim sabe que el día en que comáis de aquél se abrirán vuestros ojos y os haréis como dioses, sabedores del bien y del mal.» (Gn3: 1-5)

Si observamos detenidamente la orden de Dios en el capítulo anterior: de todo árbol del vergel podrás comer libremente, pero del árbol de la ciencia del bien y del mal no has de comer, pues el día en que de él comas morirás sin remedio. (Gn2: 16-17) y la respuesta de Eva: del fruto de los árboles del vergel podemos comer, pero respecto al fruto del árbol que está en lo interior del vergel ha dicho Elohim: no comáis de él ni lo toquéis, para que no muráis. (Gn3: 2-3), notamos que no combinan. Eva había cambiado la palabra divina y además añadió una prohibición suya: tocarlo. «Nada añadas a sus palabras, no sea que te reprenda y seas hallado mentiroso.» (Prv 30:6) Este error le va costar muy caro a nuestra protagonista, que en los ojos de la serpiente no es sólo mentirosa ${ }^{9}$ pero seguramente va a ser una presa fácil ${ }^{10}$. Según el midrash Avot de Rabbi Nathan, fue Adán quien escuchó la orden divina de Dios y al transmitírsela a Eva decidió añadir esta medida restrictiva. De tal modo, cuando Eva estaba hablando con la serpiente le dijo lo que sabía.

En Génesis Rabbah la serpiente difamó a Dios diciéndole a Eva: «De este árbol comió Él y entonces creó el mundo; así que os ha dicho: No comáis de él, para evitar que creéis otros mundos, pues toda la gente siente envidia de los de su gremio.» (Gn R 19,4). El mismo midrash narra otro argumento que utilizó la serpiente en su tentación, el argumento se jerarquía:

R. Yehuda b. R. Simón dijo: [así argumentó la serpiente]: «Todo cuanto fue creado después de su compañero, domina sobre su compañero. Los cielos [fueron creados] en el primer día y el firmamento en el segundo; ¿y no es éste que sostiene a aquéllos? El firmamento [fue creado] en el segundo y la vegetación en el tercero; ¿y no detiene éstas sus aguas? [...] y vosotros habéis sido creados después de todo lo demás, para dominarlo todo. ¡A Apresuraos a comer, antes de que cree otros mundos que os dominen!» (Gn R 19, 4)

La serpiente utilizó dos de sus poderes para que Eva cayera en su trampa: el primer es el poder seductor, que hizo soñar a Eva con la idea de ser igual a Dios. El segundo, es el poder destructor, que se basó en las mentiras y calumnias sobre Dios. Una vez tentada, Eva comió del árbol prohibido, y aquí empezó la segunda parte de la tentación: la mujer tienta a su marido: ... haciendo también copartícipe a su marido. (Gn3: 6). La imagen de Eva como engañadora, tentadora e incitadora de Adán a la desobediencia está muy presente en el pensamiento rabínico. En este midrash veremos cómo el mal empezó a infiltrarse en sus pensamientos:

[Para convencer a Eva] fue la serpiente y tocó el árbol, el cual empezó a gritar diciendo: «¡Malvado, no me toques! Pues está dicho: No me pisotee el pie del altanero ni me ahuyente la mano de los impíos. (Sal 36.12). Fue luego la serpiente

\footnotetext{
Cuando la serpiente vio que Eva mentía. (Gn. R 19, 3)

10 Moberly, 1988, 1-27. En efecto, se afirma que ésta fue la primera indicación de la estupidez de Eva y de su falta de confianza en su Creador.
} 
y le dijo a la mujer: "Ya has visto que he tocado el árbol y no me ha pasado nada; tócalo también tú, que no morirás." Fue la mujer y así lo hizo. En este momento se acercaba el ángel de la Muerte hacia ella y se dijo: "Quizás ahora muero yo y haga el Santo, bendito sea, otra mujer para dársela a Adán; así que voy a hacer que coma conmigo: si morimos, moriremos los dos juntos, y si vivimos, ambos viviremos." Cogió y comió de los frutos del árbol y dio de sus frutos también a su marido para que comiera con ella, pues está dicho: Y cogió de sus frutos y comió y dio también a su marido». (Gn3:6). (PRE13:3-4)

Otra versión exegética (Gn R 19, 5) dice que Eva tomó del árbol prohibido (la vid), comió y estrujó unas uvas para Adán. Claro, se sabe que el vino causa embriaguez y este argumento está empleado a favor del varón, para representarle como víctima de su mujer y, aunque hubiera comido del árbol prohibido, no lo hizo conscientemente. Los rabinos pensaron que Eva hizo un razonamiento antes de presentar el fruto a Adán: «Le abordó con razonamientos.» (Gn R 19, 5). Asimismo, el adverbio $\mathbf{a}$, gam que significa 'también', fue interpretado como que Eva dio comer a los animales, excepto a uno que era el ave fénix, y, por esto, siguió disfrutando de la inmortalidad:

«También» es una extensión, para indicar: dio a comer también al ganado, a los animales salvajes y a las aves. Todos le hicieron caso y comieron, excepto cierto pájaro de nombre Fénix (hol), pues está escrito: Y me dije: con mi nido moriré, como el fénix multiplicaré mis días. (Job 29,18) [...]R. Yudán b. R. Simeón decía: vive mil años, al cabo de los cuales su cuerpo se consume y se le caen las alas; pero quedan de él unos restos del tamaño de un huevo, así que le crecen nuevos miembros y revive. (Gn R 19, 5)

En otras fuentes, la serpiente no fue la única tentadora, ella misma había sido tentada por el jefe de los ángeles caídos: el diablo. En la versión griega de la Vida de Adán y Eva, se dibuja la escena del diablo intentando convencer la serpiente:

Y el diablo habló a la serpiente: «Levántate, ven hasta mí y te diré una cosa que te va a ser de provecho.» La serpiente se llegó a él, y el diablo le dijo: «Se dice que eres más sagaz que todas las fieras, por eso he venido a aprender de ti. He llegado a la conclusión de que eres mejor que todas las fieras y que éstas son amigas tuyas. $\mathrm{Y}$, sin embargo, te prosternas ante la más pequeña. ¿Por qué comes de la cizaña de Adán y su mujer en vez del fruto del paraíso? Levántate, ven acá y hagamos que Adán sea arrojado del paraíso por medio de su mujer, como nosotros fuimos arrojados del paraíso por su culpa.» Le contestó la serpiente: «Temo que se enfade el Señor conmigo.» El diablo intervino: «No temas. Conviértete sólo en un instrumento mío y yo hablaré por tu boca una palabra con la que puedas engañarlo.» (AdEvGr 16)

Sammael sería el diablo tentador según (PRE 13,2) y la tradición targúmica (TgPsJ Gn3, 6) ${ }^{11}$.

11 Castillos, Pérez, 2009, 60-63. 
Contrariamente a la Biblia Hebrea que afirma que la serpiente fue la tentadora, el Corán echa la culpa a Iblīs: el diablo. Su historia aparece varias veces en el Sagrado Libro por la importancia que tiene:

Y cuando dijimos a los ángeles: "iProsternaos ante Adán!». Se prosternaron, excepto Iblīs. Se negó y fue altivo: era de los infieles. (Cor 2. 34)

$Y$ os creamos. Luego, os formamos. Luego dijimos a los ángeles: «iProsternaos ante Adán!» Se prosternaron, excepto Iblīs. No fue de los que se prosternaron. Dijo: “¿Qué es lo que te ha impedido prosternarte cuando Yo te lo he ordenado?» Dijo: «Es que soy mejor que él. A mí me creaste de fuego, mientras que a él le creaste de arcilla». Dijo: "iDesciende, pues, de aqui! ¡No vas a echártelas de soberbio en este lugar...! ;Sal, pues, eres de los despreciables!» (Cor 7. 11-13)

Cuando tu Señor dijo a los ángeles: «Voy a crear a un mortal de arcilla y, cuando lo haya formado armoniosamente e infundido en él de Mi Espiritu, jcaed prosternados ante él!» Los ángeles se prosternaron, todos juntos, salvo Iblīs, que se mostró altivo y fue de los infieles. Dijo: "iIblīs! ¿Qué es lo que te ha impedido prosternarte ante lo que con Mis manos he creado? ¿Ha sido la altivez, la arrogancia?» Dijo: «Yo soy mejor que él. A mi me creaste de fuego, mientras que a él le creaste de arcilla». Dijo: "iSal de aqui! ;Eres un maldito! ¡Mi maldición te perseguirá hasta el día del Juicio!» (Cor 38. 71-77)

$Y$ cuando dijimos a los ángeles: "iProsternaos ante Adán!». Se prosternaron, excepto Iblīs, que dijo: “¿Voy a prosternarme ante quien has creado de arcilla?» (Cor 17.61)

Y cuando dijimos a los ángeles: "iProsternaos ante Adán!» Se prosternaron, excepto Iblīs, que se negó. (Cor 20. 116)

La tradición islámica desarrolla con más detalles la historia de Iblīs. Fue originalmente llamado 'azāzīil ${ }^{12}$ y era el padre de los ŷins. Antes de la creación de Adán, los ŷins reinaban sobre la tierra, tenían también la capacidad de navegar en el espacio, pero derramaban mucha sangre. Iblīs era el único que adoraba Dios. Por eso, fue recompensado y ascendido al rango de los ángeles ${ }^{13}$. Era el más honorable e inteligente. Tenía cuatro alas y una muy buena apariencia. Ka ‘b al- Aḥbār afirma que tiene siete nombres que cambiaban según los siete cielos ${ }^{14}$. Su nombre viene citado en la libreta protegida u oculta ${ }^{15}$ y se precisa que se deriva de al-iblās que es la exclusión. Según Al-Rabġūzīi ${ }^{16}$, Iblīs estaba encargado del paraíso y fue él quien enseñaba la sabiduría a los ángeles. Un día leyó en la libreta protegida que uno de los ángeles sería maldito. Isrāfî $1{ }^{17}$ leyó también esto, y lo anunció a todos los ángeles y rogaron a Iblīs que rezara para ellos porque estaba muy cerca de Dios y gracias a

12 עזאזל ' $a z \bar{a} z \bar{l} l$ es un término enigmático que se encuentra en la Biblia así como en algunos apócrifos. Se refiere a un antiguo demonio que habitaba el en el desierto en el antiguo Canaán.

13 Sin serlo verdaderamente, porque Dios le creó a partir del fuego y los ángeles a partir de la luz.

14 En el primer cielo de la tierra se llamaba 'ābid, en el segundo Zāhid, en el tercero 'ārif, en el cuarto al-waliy, at-taqiy en el quinto, al-jāzin en el sexto y 'azāzīl en el último cielo.

15 Al-lawh al-mahfūz, הלוח הגנוז es un libro donde Dios inscribió el destino de cualquier criatura antes de crearla. Faher, 2003, 30.

16 Al-Rabğūzì, 1995, 22.

17 Isrāfill es uno de los cuatro arcángeles islámicos junto con Mījā'̄̄l, Ŷibrīl y 'Azrā'̄̄l. Es encargado de soplar la trompeta sobre una roca en Jerusalén para anunciar el día de la resurrección. 
sus rezos Dios protegió a todos los ángeles. Sin embargo, Iblīs olvidó rezar por sí mismo y por esto no fue protegido y recibió la maldición. Al acabar la creación de Adán, Dios reunió a todos los ángeles para honrar a su criatura. Les pidió que se prosternasen (Cor 2. 34) todos obedecieron salvo Iblīs. La causa principal de esta desobediencia está mencionada en el texto coránico: el orgullo. Interrumpido, Iblīs lo justificó por haber sido creado del fuego, razón por la que se sintió superior a Adán, que había sido creado de arcilla (Cor 38. 71-77) (Cor 17. 61). Dios le maldijo y le excluyó del paraíso hasta el final de los tiempos. Su destino final sería el infierno: del fuego se creó y al fuego volvería. Mientras tanto Adán y Eva vivían felizmente en el Paraíso:

Estuvieron en el paraíso quinientos años como los de este mundo en la más completa felicidad y en el más feliz de los estados. Adán bajaba del estrado y se paseaba por los lugares del paraíso y Eva lo seguía, arrastrando sus brocados. Y siempre que pasaban de un palacio a otro, los ángeles esparcían sobre ellos confeti del paraíso hasta que volvían a su estrado ${ }^{18}$.

Iblīs sintió aún más envidia de la pareja, y pensaba cómo podía expulsarles también del paraíso. Se quedó trescientos años rezando cerca de la puerta del Edén ${ }^{19}$ hasta que un día vio el pavo real saliendo del jardín ${ }^{20}$, se dirigió hacia él y le dijo palabras buenas:

¡Oh ave maravillosa, con buen aspecto y voz agradable! ¿Qué ave eres del paraíso?». Le contestó: «Soy el pavo real, ¿Qué te pasa, oh individuo, como si desearas o temieras hacer una petición?». Iblīs le explicó: «Soy uno de los ángeles del grupo de los querubines que no dejaron, ni un solo momento, de hacer alabanzas, y contemplo el paraíso y todo lo que Dios preparó allí para su gente. ¿Puedes introducirme en él y yo te enseñaré tres palabras que quien las diga tendrá la juventud eterna, la salud y la inmortalidad?». El pavo contestó: «Ay de ti, oh individuo, ¿la gente del paraíso morirá?». Contestó: «Sí, morirán, serán viejos y enfermarán, excepto quien diga estas palabras.»Y Y se lo juró. Entonces, el pavo real se fio de él, ya que pensó que quien jura por Dios no es embustero. El pavo le rogó: «Oh persona, necesito saber estas palabras, pero temo que Riḍ̂ān ${ }^{21}$ me pregunte, así que ve junto a la serpiente, la señora de los animales del paraíso, que te introducirá allí2 ${ }^{2}$.

El Corán no proporciona estos detalles y no menciona la serpiente, sólo es Iblīs quien tienta a la pareja. Tabarī describe a la serpiente diciendo que se parecía al camello, tenía cuatro patas y era la más hermosa de todas las bestias ${ }^{23}$. En otra leyenda, la serpiente aparece con cuatro alas adornadas de rojo y verde. Eva solía

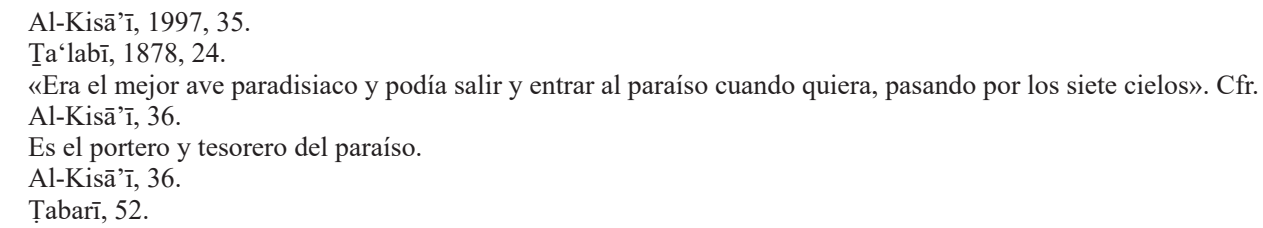


charlar con ella ${ }^{24}$. Al-Kisā’̄̄ basándose en la descripción de Ka’b al-aḥbār, nos pinta la imagen de la serpiente detalladamente:

La serpiente tenía entonces, forma y patas como el camello, una cola como una alfombra abqarí de colores rojo, amarillo, verde, blanco y negro; una crin de perlas, mechones de Jacinto y dos ojos como Venus y Júpiter, con aroma de almizcle mezclado con ámbar. Su morada era el paraíso de al-ma’wa y su emplazamiento, la orilla del Kawtar... ${ }^{25}$.

Iblīs había quedado cerca de la puerta del paraíso hasta que llegó la serpiente e igualmente como hizo con el pavo real, le sedujo con sus palabras bien elegidas y le suplicó que le dejara entrar en el paraíso; le sugirió que se convirtiese en aire y que entrara en su boca ${ }^{26}$. La serpiente aceptó y de esta manera Iblīs entró al paraíso. Tabarī afirma que cuando Adán entró al paraíso y vio la munificencia allí, dijo: «Ojalá pudiera vivir aquí para siempre.» Iblīs le escuchó y entendió que era el punto débil del hombre, así, le engañó con lo que más le tentaba: su deseo de inmortalidad. No obstante, el Corán afirma que Dios advirtió a Adán de Iblīs a sabiendas que iba a hacer todo para excluirlo del paraíso: Dijimos: " ¡Adán! Éste es un enemigo para ti y para tu esposa ;Que no os expulse del Jardín; si no serás desgraciado!». (Cor 20. 116)

En ninguna parte del Corán se encuentra la mínima alusión de que Eva fue engañada primero o que ella engañó su marido. Simultáneamente, los dos fueron engañados por Iblīs. De esta forma, Eva no lleva el traje de tentadora que lo lleva en la Biblia. Iblīs susurró a ambos para que comiesen del árbol de la inmortalidad: Pero el Demonio le insinuó el mal. Dijo: "¡Adán! ¿Te indico el árbol de la inmortalidad $y$ de un dominio imperecedero?». (Cor 20. 117)

Y en otro versículo les susurró para comer del árbol y convertirse en ángeles e inmortales:

Pero el Demonio les insinuó el mal, mostrándoles su escondida desnudez, y dijo: «Vuestro Señor no os ha prohibido acercaros a este árbol sino por temor de que os convirtáis en ángeles u os hagáis inmortales». (Cor 2. 22)

A pesar de la advertencia de Dios la pareja escuchó las palabras engañadoras de Iblīs. Hicieron esto porque simplemente, este último les juró en nombre de Dios, y nunca pensaron que era mentira: «iDe veras, os aconsejo bien!». Ambos comieron y se olvidaron de la alianza que hicieron con Dios, y el uso del plural en los versículos coránicos pone esta idea de relieve: fueron los dos culpables. El Corán iguala la responsabilidad de transgresión entre hombre y mujer: comieron de él. (Cor 20. 118), y cuando hubieron gustado ambos del árbol. (Cor 2. 22).

La tradición islámica influida por la tradición judeocristiana, desarrolló un gran mosaico de la transgresión. Casi igual a la versión judía, la transgresión giró alrededor de Eva y la serpiente. Ta'labī narra que Iblīs se dirigió hacia la pareja y empezó a llorar diciéndoles que se preocupaba mucho por ellos, porque iban a

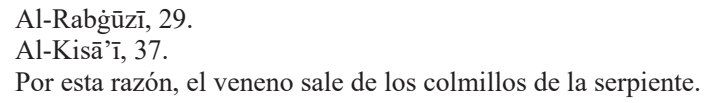


envejecer y morir; por consiguiente, iban a dejar toda esta vida de lujo, pero si comieran del árbol de la eternidad no les sucedería nada. Al principio dijeron que no podían comer porque era la orden de Dios, pero al oírle jurando, comió Eva y luego Adán $^{27}$. Ibn Ishạa y Sa'̄id Ibn al-Musayab decían que Adán sólo comió del árbol, cuando estaba inconsciente porque Eva le dio vino hasta que se emborrachó $^{28}$. Ibn Katīi insistió sobre el hecho de que Eva comió antes de su marido, basándose en el ḥadīz:

$$
\text { 》الو لا بنو إسر ائيل لم بخنز اللحمو لو لا حواء لم تخن اثثى زوجها 《 }
$$

o sea, por culpa de los israelitas se apestó la carne y por culpa de Eva las mujeres engañarán a sus hombres ${ }^{29}$.

Otra versión narra que Iblīs se dirigió primero a Adán, pero cuando este último no le hizo caso, se fue a Eva pensando que el corazón de la mujer era más sensible. Le convenció que si comía del árbol nunca moriría y se quedaría por siempre en el Edén. Al oírlo, Eva se levantó y se dirigió hacia el árbol. Anduvo a diez trancos largos y comió del trigo. Cuando rompió la espiga el árbol lloró. De allí se explica la menstruación mensual que recordará el legado de la mujer hasta el final del mundo. La menstruación dura entre tres y diez días. Tres porque Eva anduvo con sus pies, cogió el trigo con sus manos y lo comió con su boca, y diez porque dio diez pasos para llegar al árbol. En adición, al andar, Eva respiró cuarenta alientos, se cuenta un día para cada aliento, lo que nos da en total cuarenta días de trabajo de parto. Luego incitó a su marido para comer. Adán se olvidó totalmente del pacto con Dios; puso el grano en su boca y lo masticó. Cuando alcanzó su garganta, se acordó Adán de las palabras de Dios, mas no podía tragarlo ni devolverlo. Para impedir que bajara hasta la laringe. Adán apretó su garganta con la mano, y el grano se transformó en una bola a nivel de la laringe lo que es conocido como «manzana de Adán»; por eso, el hombre tiene esta bola y la mujer no ${ }^{30}$. Según Wahb ibn Munabbih fue Iblīs quien puso el fruto en las manos de Eva, haciéndola aparecer muy guapa en los ojos de Adán hasta que tuviera ganas de ella. Sin embargo, le chantajeó: sólo le podría tocar si comiera del fruto ${ }^{31}$.

De nuevo, aparece la sexualidad ${ }^{32}$ de Eva como causa de la tragedia en Tosefta y Génesis Rabbah. La serpiente vio Eva haciendo el amor con Adán y sintió pasión por ella. Así que quiso estar en el lugar de Adán:

¿Con qué pecado los asaltó aquel ser malvado? Pues tan pronto como los vio dedicados a las funciones naturales, sintió pasión por ella. (Gn R 18.6)

La serpiente primitiva deseó matar a Adán para poder casarse con Eva. (Tosefta Sota 4. 17)

\footnotetext{
Ta'labī, 25.

28 Ibn al-Atîr, 1979, 35. Sin embargo, el Corán afirma que el vino del Edén no emborracha: clara, delicia de los bebedores, que no aturdirá ni se agotará. (Cor 37. 46-47) lo que mantiene la hipótesis de que no se trata de $\hat{Y}$ annat al-juld o el edén final.

29 Ibn Katīir, 40.

30 Al-Rabğūzì, 30-31.

31 Tabarī, 253.

32 Davidson, 1988, 5-21.
} 


\section{La tragedia}

El texto bíblico ha anunciado que la consecuencia inmediata de comer del árbol prohibido sería la muerte (Gn2: 17). No obstante, cuando la pareja comieron del fruto no murieron en seguida pero perdieron la inmortalidad y emprendieron sus caminos hacia la muerte. La consecuencia directa de la transgresión fue la toma de conciencia de su desnudez y la vergüenza: ábriéronse entonces los ojos de ambos y comprendieron que estaban desnudos, por lo cual entretejieron follaje de higuera e hiciéronse unos ceñidores. (Gn3: 7)

Los rabinos explican el hecho de abrir los ojos era en sí mismo un castigo para que se dieran cuenta y vieran a cuántas personas habían destruido por su culpa (Gn R 19, 6). El midrash Pirqé de Rabbi Eliezer describe los vestidos que llevaba la pareja antes de transgredir:

¿Cuál era el vestido del primer hombre? Una piel de ónice, y una nube de gloria lo cubría. Mas cuando comió de los frutos del árbol fue desvestido de su piel de uña y se vio a sí mismo desnudo, al tiempo que la nube de gloria levantándose se alejaba de él. (PRE 14, 2)

Filón ve que no se trata de la desnudez corporal de Adán y Eva sino de la desnudez de sus almas y la desnudez de la virtud. Darse cuenta de que estaban desnudos puede explicar, por un lado, que perdieron algo como acabamos de ver; sus trajes de gloria, su inocencia sexual y sobre todo su inmortalidad. Por el otro lado, ganaron algo muy importante que sería la toma de conciencia de sus cuerpos. Totalmente desnudos, Adán y Eva empezaron a taparse los cuerpos con hojas de higuera:

Dijo R. Simeón ben Yojay: Es la hoja que dio al mundo ocasión de morir. Dijo R. Yisjaq: Con tus obras has destrozado, así que, ¡coge el hilo y cose! E hiciéronse unos ceñidores $(3,7)$. Dijo R. Abba bar Kahana: no está escrito «ceñidor» sino «ceñidores», es decir, diversos tipos de vestimenta: túnicas, capas y mantos. E igual que éstos se hacen para el hombre, asimismo para la mujer se hacen ceñidores, sombreros y velos bordados. (Gn R 19, 6)

Según Ginzberg ${ }^{33}$, los árboles del Edén no quisieron ayudar a Adán y Eva dándoles sus hojas, excepto la higuera que les permitió tomar de sus hojas porque ella misma había sido el árbol prohibido. A continuación, Dios preguntó a Adán por qué comió del árbol, su respuesta fue culpar a la mujer: la mujer que me pusiste junto a mí, ésa me ha dado del árbol y he comido. (Gn 3: 12). Adán no reconoció su error y no quiso afrontar la responsabilidad de sus actos ya que el hecho de preguntarle podría ser una oportunidad que le ofrecía Dios para admitir su error. Desgraciadamente, culpó a Eva por darle el fruto, e implícitamente culpó a Dios por haber creado a la mujer. Ya no es hueso de mis huesos ni carne de mi carne, sino la mujer que pusiste junto a mí. Adán se olvidó de su soledad y de la ayuda idónea que necesitaba antes, ahora la mujer se convirtió en una carga. Es como si estuviera haciendo reproches acerca de la mujer que Dios creó especialmente para él; se puede considerar

33 Ginzberg, 1998, II, 75. 
como un acto de ingratitud hacia su creador ${ }^{34}$. Luego, Dios dirigió la palabra por la primera vez a la mujer ${ }^{35}$, preguntándole por qué comió. A diferencia del hombre que dijo me ha dado, Eva culpó a la serpiente diciendo me sedujo: y la mujer contestó: La serpiente me sedujo y he comido. (Gn3: 13). Filón explica que dar es propio de la sensibilidad, de la mujer, y engañar es propio del placer «Lo propio es engañar e inducir a error.». Él cree que la mujer fue víctima de su arrogancia:

El placer pues ha engañado, completamente, a la ciega sensibilidad en la aprensión de los objetos, ya que, cuando ella hubiera podido volverse hacia la inteligencia y recibir su apoyo, se lo ha impedido, conduciéndola hacia lo que sólo se puede percibir exteriormente, y tornándola ávida de lo que produce placer, para que la sensibilidad, ciega como es, fuera guiada por un guía ciego; el objeto sensible; y, a su vez, la inteligencia, guiada por ambos guías incapaces de ver viniera a parar en tierra y no fuera ya dueña de sí. (Inter. III, XXXV, 109)

El midrash PRE 14, 2 describe el interrogativo de la pareja y cómo respondió Eva. Parece que este interrogativo sigue un orden decreciente: Dios empezó por Adán, luego Eva y al final la serpiente, aunque después, respecto al castigo, será completamente lo contrario. En este propósito los rabinos afirman que cuando se trata de excelencia, se comienza con el más grande o el mejor para acabar con el menor o el peor. Mas cuando se trata de maldiciones la cosa es al revés, o sea que Adán recibió menor maldición que Eva y la serpiente (Sifra, Shemini 1:39). Después de castigar la serpiente, Dios anunció el juico de Eva: Multiplicaré sobremanera, los sufrimientos de tu gravidez, con sufrimiento parirás hijos y hacia tu marido será tu tendencia y

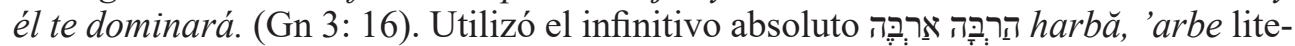
ralmente «multiplicando, multiplicaré» lo que sirvió para intensificar el dolor. Filón ve que la pena y el sufrimiento son experiencias propias de la mujer, ya que lo que le procuró el placer, le procuraría el sufrimiento. También Dios condenó la mujer de vivir subordinada al hombre limitando su independencia y libertad. En PRE, se desarrollan las nueve maldiciones de la mujer:

A la mujer le impuso nueve maldiciones más la muerte; los dolores de la sangre de su menstruación y de la sangre de su virginidad; los dolores del embarazo y del parto, los dolores de criar los hijos; la cabeza cubierta como el que lleva luto, y agujereó su oreja como esclavo perpetuo y como sierva que está para servir a su marido y no es aceptada entre los testigos. Y después de esto, la muerte. (PRE 14. 4)

La literatura rabínica presentó a Eva como la causa del drama de la humanidad, ya que no se limitó a transgredir sino hizo que su marido transgrediera también y fue ella quien trajo la muerte:

Preguntaron al R. Yehosúa: [...] ¿por qué el hombre sale con la cabeza descubierta y la mujer con la cabeza cubierta?, les dijo: es como que ha cometido una

Cfr. (Inter. III, XXXV, 109).

35 Antes, Dios se dirigía implícitamente a la mujer utilizando la segunda persona del plural. Los rabinos insisten sobre el hecho de que Dios nunca habló directamente con mujeres salvo Eva y Sara debido a motivos concretos. A Rebeca y a Agar les habló a través de un intermediario «ángel». Gn R 20, 6. 
transgresión y siente vergüenza de la gente; por esto sale cubierta. ¿Por qué ellas marchan primeras en el cortejo fúnebre?, les respondió: Porque trajeron la muerte al mundo; por eso marchan ellas primeras del cortejo fúnebre, como está escrito: Y él es conducido al cementerio... y tras él todos los hombres desfilan, y un sinnúmero ante él (Job 21, 38s). ¿Y por qué le fue dado el precepto de menstruación?, porque vertió la sangre del primer hombre, por eso le fue dado el precepto de menstruación... (Gn R 17, 8)

En Avot de Rabbi Nathan A, los rabinos afirmaron que Dios creó a Adán, luego a Eva, se casaron, transgredieron y fueron castigados todos en el mismo día.

También la primera consecuencia de la transgresión de la pareja viene citada en el Corán; era la conciencia de su desnudez y la vergüenza: les hizo, pues, caer dolosamente. Y cuando hubieron gustado ambos del árbol, se les reveló su desnudez y comenzaron a cubrirse con hojas del Jardín. (Cor 7. 22); comieron de él, se les reveló su desnudez y comenzaron a cubrirse con hojas del Jardín. (Cor 20. 121)

Los tradicionalistas y exegetas desarrollaron más las consecuencias de la transgresión, ofreciendo un gran abanico de versiones. Ta ${ }^{6} l a b \overline{1}^{-36}$ narra que al comer del árbol, a Adán se le cayeron su trono, su anillo y todo lo que llevaba, a Eva se le cayeron sus adornos y su vestido. Además se les cayó la piel del paraíso y sólo quedaron trocitos pequeños en las puntas de los dedos para recordarles siempre cómo habían sido. Sin embargo, Ibn Katīir ${ }^{37}$ dice que se dieron cuenta de su desnudez porque antes tenían luz que cubría sus partes genitales. Wahb Ibn Munabbah explica el error común que cometieron muchos qușșāṣ al decir que la pareja llevaba ropa,

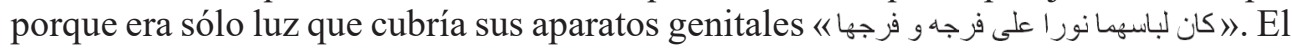
Corán no precisó qué tipo de hojas utilizó la pareja para cubrirse pero la tradición es muy rica en este propósito. $\underline{T a}^{\prime} \mathrm{lab}^{-38}$ narró que ningún árbol aceptó darles sus hojas, excepto la higuera, por esta razón Dios honró a este árbol llamando una azora attīn «la higuera». Al-Rabg் $\bar{u} z \overline{1}^{39}$, compartió la misma idea, ampliando la descripción; dijo que la higuera les dio cinco hojas. Después de salir del paraíso, la primera hoja fue comida por el venado y se convirtió en almizcle. La segunda fue comida por el buey y se convirtió en ámbar. La tercera fue comida por la abeja y se transformó en miel. El gusano comió la cuarta y produjo la seda. Y la quinta fue plantada por Adán y floreció con algodón. En cuanto al juicio de Eva, el texto coránico no distinguió entre hombre y mujer en el castigo. Se precisó que ambos se dieron cuenta de su error, se arrepintieron mucho y pidieron perdón, Dios les castigó sólo expulsándolos fuera del Jardín y estableciendo una enemistad entre ellos e Iblīs:

Dijeron: « ¡Señor! Hemos sido injustos con nosotros mismos. Si no nos perdonas y Te apiadas de nosotros, seremos, ciertamente, de los que pierden». Dijo: «jDescended! Seréis enemigos unos de otros. La tierra será por algún tiempo vuestra morada y lugar de disfrute» (Cor 7. 23-24)

$Y$ dijimos: "¡Descended! Seréis enemigos unos de otros. La tierra será por algún tiempo vuestra morada y lugar de disfrute». (Cor 2. 36)

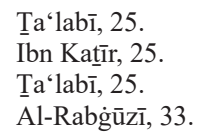


La tradición islámica parece más severa en cuanto al juicio de Eva. Ya que recibió veinticinco penalidades, diez eran las mismas que Adán ${ }^{40}$ y quince más, especialmente para ella y para todas sus hijas. La menstruación fue la primera sanción, porque cuando Eva cogió el fruto del árbol, le hizo sangrar. Ibn Zayd dijo: «Si no hiciera Eva lo que hizo, ninguna de las mujeres tendría menstruación, ni dolores de embarazo, ni de parto y sería inteligente. ${ }^{41} \gg$. Ṭabarī dijo que Dios anunció a Adán cómo va a castigar a Eva:

La haré sangrar una vez al mes, tal como hizo sangrar este árbol. Voy a hacerla tonta, aunque originalmente la creé de un temperamento suave. Le haré tener un doloroso embarazo y un parto, aunque originalmente se le hice fácil. ${ }^{42}$

La pesadez del embarazo, los dolores del parto y el dolor del nacimiento son las siguientes sanciones; de aquí se entiende por qué el Islam insistió sobre el amor y respeto de la madre: «su madre le llevó sufriendo pena tras pena y le destetó a los dos años» (Cor 31. 14). En adición, Dios disminuyó su inteligencia y su religiosidad, 《). Esto hizo que la mujer recibiera, en la herencia la mitad de la porción del hombre: Allah os ordena lo siguiente en lo que toca a vuestros hijos: que la porción del varón equivalga a la de dos hembras. (Cor 4. 11) y la hizo sumisa al hombre, mejor dicho, que él tuviera autoridad sobre ella: los hombres tienen autoridad sobre las mujeres en virtud de la preferencia que Allah ha dado a unos más que a otros y de los bienes que gastan. (Cor 4. 34). Consecuencia de ello, no habían profetas ni sultanas, tampoco podían participar en las guerras, viajar solas o pedir el divorcio. No se podían reunir con hombres; el profeta advirtió de que no se reuniera un hombre con una mujer extraña porque Iblīs estaría con ellos:

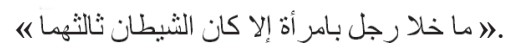

Por añadidura, no se podía saludar a las mujeres porque era un acto de agresión a su intimidad y pureza, así como la de su familia. Al final, Dios impuso al- 'idda ${ }^{43}$ sobre las mujeres. Se trata del período legal que debe esperar la mujer absteniéndose de relaciones sexuales después de su repudio, o la muerte de su marido ${ }^{44}$ :

Las repudiadas deberán esperar tres menstruaciones. No les es lícito ocultar lo que Allah ha creado en su seno si es que creen en Allah y en el último Día. Durante esta espera, sus esposos tienen pleno derecho a tomarlas de nuevo si desean la reconciliación. Ellas tienen derechos equivalentes a sus obligaciones, conforme al uso, pero los hombres están un grado por encima de ellas. Allah es poderoso, sabio. (Cor 2. 228).

Las viudas que dejéis deben esperar cuatro meses y diez días; pasado ese tiempo, no seréis ya responsables de lo que ellas dispongan de sí mismas conforme al uso. Allah está bien informado de lo que hacéis. (Cor 2.234).

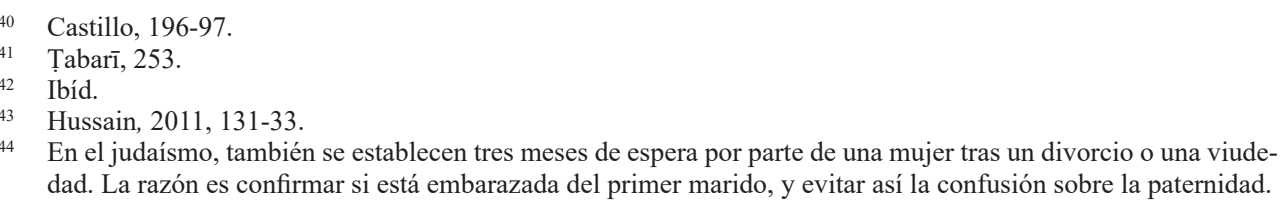
dad. La razón es confirmar si está embarazada del primer marido, y evitar así la confusión sobre la paternidad. 
Una vez acabado el juicio, Dios ordenó a dos ángeles, Gabriel y Miguel, que expulsaran a Eva y a su marido del paraíso ${ }^{45}$. Salieron del paraíso el viernes ${ }^{46}$ con llanto y lágrimas, lamentando y arrepintiéndose de lo que hicieron ${ }^{47}$.

\section{Cuando el final es el comienzo}

Una vez expulsados del paraíso, parece que el hecho transgresor operó un cambio sobre Adán, quien tomó conciencia de sí mismo y de su mujer. La relación y química entre hombre y mujer sólo se hizo posible fuera del paraíso. La Biblia afirma el nacimiento del deseo sexual y el instinto de reproducción; el hombre conoció a Eva, su mujer. (Gn4. 1). El verbo ידָּ yŏdé 'a (conoció), significa en este contexto que tuvieron relaciones sexuales. Los rabinos afirmaron que ninguna criatura habría tenido relaciones sexuales antes de Adán y Eva. También interpretaron que Eva fue la tentadora y serpiente de Adán (Gn R 20,11), le excitó y estimuló su deseo sexual:

R. Huna y R. Yaaqob, en nombre de R. Abba dijeron: Ninguna criatura tuvo nunca relaciones sexuales antes que el primer hombre, pues aquí no está escrito «un hombre conoció», sino y «el hombre conoció» que quiere decir: dio a conocer la conducta sexual a todos. Conoció de qué manera le había sido arrebatada la tranquilidad; conoció lo que le había hecho su serpiente. Dijo R. Aja: la serpiente fue tu serpiente, y tú fuiste la serpiente de Adán. (Gn R 22, 2)

En el midrash (Gn R 22, 2), se afirma que todos estos acontecimientos ocurrieron en el mismo día: Adán y Eva fueron creados, se casaron, vivieron en el paraíso, transgredieron, fueron expulsados, cohabitaron y tuvieron sus niños. En texto bíblico, Eva dijo: he adquirido un varón gracias a Yahvé. (Gn4. 1), el uso de la palabra varón איש posibilidad de que este bebé fuese el primer varón que tenía y que antes de él había parido a niñas. En la tradición targúmica y midrásica, la expresión "gracias a Yahvé» se entiende como que Eva engendró con Sammael, el ángel caído: «He adquirido a un hombre, el ángel de YHWH» (TgPsJ Gn4. 1). Los rabinos explicaron la misma expresión de otro modo:

Sin embargo, con la ayuda de YHWH enseña que en el pasado Adán fue creado de la tierra, y Eva de Adán; a partir de entonces a nuestra imagen, a semejanza nuestra (Gn1. 26); ni hombre sin mujer, ni mujer sin hombre, y ninguno de los dos sin la Shekinah. (Gn R 22, 2)

Caín ${ }^{48}$ fue el primogénito. Eva parió luego a su hermano Abel; más adelante, volvió a parir a su hermano Abel. (Gn4. 2). Según el pensamiento rabínico, Caín y Abel fueron concebidos en el mismo momento, ya que no se trata de otro embarazo,

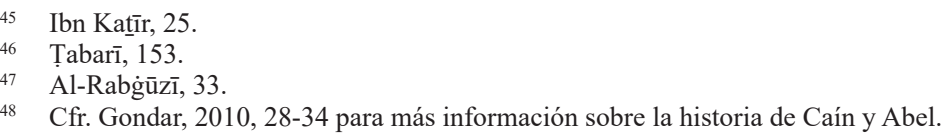


sino de un nacimiento adicional. «R. Yehosúa ben Qorjah dijo: subieron al lecho dos y bajaron siete» (Gn R 22. 3). Los siete serían Adán, Eva, Caín, Abel, dos hermanas gemelas de Caín y una sola de Abel. La Biblia no menciona el número de hijos e hijas, tampoco sus nombres, excepto tres que son Caín, Abel y Set. Después de su pecado Eva se arrepintió mucho, y la versión latina de la vida de Adán y Eva describe su penitencia; se sumergió cuarenta días en el Tigris ${ }^{49}$ para purificarse, dejando sólo su cabeza fuera.

En cuanto a la tradición islámica, el Corán hace escasa referencia de la vida de la pareja después de su expulsión del paraíso. Sin embargo, las historias tradicionales Abundan en este tema. Ta ${ }^{6} l a b{ }^{-50}$ citó que Eva se estableció después de su expulsión en Ŷedda y Adán en Serendib ${ }^{51}$. Se quedaron cada uno cien años por sí solo. Ibn 'Abbās afirmó que lloraron ${ }^{52}$ doscientos años y no comieron ni bebieron durante cua-

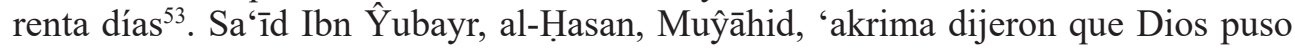
un gran diamante en la actual Meca y ordenó a Adán que se fuera a peregrinar allí para perdonarle..$^{54}$ En otra versión, Dios le ordenó ir a la Meca para construir la santa casa de Dios $a l-k a$ ' $b a$, después, Ŷibrīl le enseñó el ritual de la peregrinación ${ }^{55}$. Adán hizo lo que Dios le pidió y fue perdonado. Le separaba de Eva unas siete parasangas $^{56}$, quien estaba muy triste por no haber visto su marido durante todo este tiempo. Cuando vio de repente un hombre proviniendo de la Meca dirigiéndose hacia ella, supo que no habría ningún hombre sobre la tierra salvo Adán, por esto estaba muy feliz y corrió hacia él. Se acercaron el uno del otro en un lugar que se llama muzdalifa ${ }^{57}$, luego se reconocieron el uno al otro en la colina de 'arafāt ${ }^{58}$, después bajaron a Minā, donde Adán pidió a Dios que perdonara a su mujer. Su deseo se realizó y así volvió con Eva para vivir en Serendib, porque su tierra era muy fértil ${ }^{59}$. El Corán precisa que Dios les ofreció ocho parejas de animales: Cuatro parejas de reses, una de ganado ovino y otra de ganado caprino, [...], una de ganado camélido y otra de ganado bovino. (Cor 6. 143-44)

Cuando Adán tenía frío, Dios le ordenó que matara un cordero y mandó Ŷibrīl para enseñar a Eva como hilar y tejer ${ }^{60}$. Así pues, hizo Eva una chilaba para su marido y un escudo y un velo para ella ${ }^{61}$. Al-Rabgù̄zī enunció que lo que había cultivado Adán germinó abundantemente al contrario de su mujer, germinó escasamente. Igualmente, Ŷibrīl enseñó a Adán cómo cocinar el pan. Luego dividió la hogaza en tres partes; dio dos a Adán y una a Eva ${ }^{62}$. Mientras que Adán comió toda su porción, Eva dejó la mitad. Ŷibrīl le dijo: «Si hubieras comido todo el trozo como tu marido,

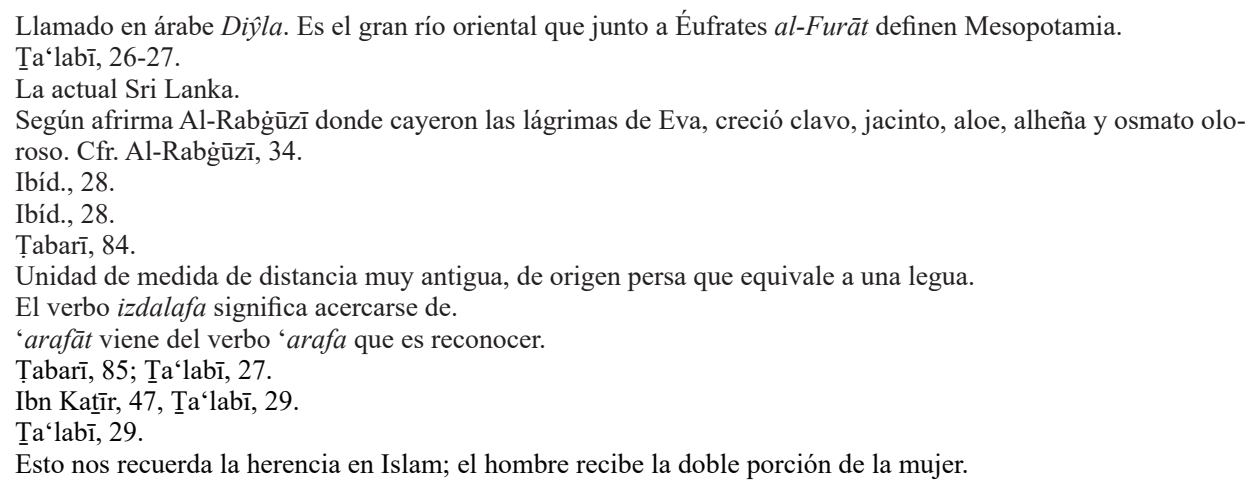


ninguno de tus hijos tendría hambre hasta el día del juicio.» ${ }^{63}$. Según Ibn Katīr, Eva hizo todas las tareas domésticas: tejer, limpiar, cocinar, amasar, etc. ${ }^{64}$. De modo similar, Ŷibrīl enseñó a Adán cómo debería acostarse con Eva, porque después de la expulsión cada uno dormía en un lado. Luego le preguntó a Adán qué le parecía Eva. Contestó: «Buena esposa», zawg̀a șāliḥa. En 'arafāt Adán copuló con Eva y se quedó embarazada, su carga era luz (Cor 7, 189). Cuando creció su barriga y pesó más, vino Iblīs y le susurró una segunda vez a la mujer y le dijo que estaba embarazada de un animal y que le iba a ayudar para que fuera un ser humano bajo una sola condición: al nacer tendría que llamarle Hārit que era otro nombre de Iblīs. Al dar la luz, Eva cumplió su promesa y llamó el bebé Hāriț, que murió enseguida ${ }^{65}$. La tradición afirma que Eva parió setenta veces, y cada vez, eran gemelos; un niño y una niña ${ }^{66}$. Se precisa que dio luz a Set $\underline{t} \bar{\imath} S$ justo después de cincuenta años de la muerte de Abel y que no tenía gemela ${ }^{67}$.

\section{La muerte de Eva}

El texto bíblico no alude a su muerte, pero en el midrash (Gn R 58. 2) se afirma que

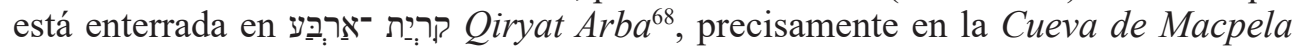
מערת המכפלה , denominada también la cueva de doble tumbas ${ }^{69}$. Podemos decir que Eva murió dos veces; la primera vez fue una muerte espiritual cuando comió del árbol prohibido, así se rompió su relación con Dios, y la segunda vez fue una muerte física, que es el destino de todo ser humano. Tampoco el Corán mencionó la muerte de Eva. Ibn Ka'b dijo que escuchaba el profeta diciendo: «cuando Adán estaba moribundo y que los ángeles le trajeron su sudario del paraíso, Eva se acercaba, pero él gritó: ¡Déjame con los ángeles que ha mandado Dios! ¡Déjame! Todo lo que me está pasando es por tu culpa. ¡Vete! ${ }^{70} \gg$. Eva no supo que Adán falleció, sólo se lo dijeron después de enterrarle, por esto empezó a gritar, a abofetear su rostro y a golpear su pecho. Se quedó cerca de su tumba cuarenta días sin comer ni beber ${ }^{71}$. Ibn Katīr dijo que vivió un año después de la muerte de su marido, pero Al-Kisā’̄ nos informó que en el día cuarenta después de la muerte de Adán vino el ángel de la muerte y dio a Eva de la misma bebida que dio a Adán, luego sus hijas la lavaron y la amortajaron en un sudario del paraíso y fue enterrada con su marido ${ }^{72}$. Se dice que fue enterrada

63 Cfr. Al-Rabḡūzī, 34. Parece que Eva no comió porque no tenía confianza en Adán, también hay otra opinión que afirma que Eva no comió la hogaza entera porque antes cuando estaba sola en Ŷidda pescó un pez del mar, lo asó sobe una roca caliente y lo comió.

64 Ibn Katīir, 43.

65 Al-Rabg̀ūzī, 34. En el mismo propósito, Țabarī narró que Eva estuvo embarazada tres veces y cada vez perdía al bebé. Iblīs aprovechó esto, y le prometió a Adán que iba a tener un hijo muy guapo y que no iba a morir. Al nacer el niño, notó Adán que era guapo y le llamó 'abd al- Harịt o sirviente del Harīth. Dios les castigó y perdieron otra vez a su bebé.

66 Al-Rabg் ūzī, 34.

67 Ibn al-atīir, 47.

68 Este lugar se mencionó en la Biblia Gn 23. 2. La tradición considera que es donde fueron enterrados Adán y Eva, Abraham y Sarah, Isaac y Rebeca y Jacob y Lea.

69 En el judaísmo, es el segundo lugar santo después del Templo de Jerusalén. En el Islam se llama la mezquita de Abraham y es el cuarto lugar santo después de la Meca, la mezquita de la Medina y al-Aqșā.

70 Ibn Katīir, 48.

71 Al-Kisā'̄i, 78-79.

72 Ibíd. 
en una cueva del monte Abū Qubays en la $\mathrm{Meca}^{73}$. Otra tradición con mucho arraigo cuenta que, Noé llevó los dos cadáveres de la pareja, los puso en ataúdes en su barco y les depositó en Jerusalén ${ }^{74}$.

\section{Conclusiones}

Las tradiciones han estado siempre en simbiosis, por esto, no han parado de modificarse, cambiarse y desde luego de enriquecerse. Indudablemente, la tradición islámica se vio enriquecida y diversificada por la herencia que recibió del Cristianismo y sobre todo del Judaísmo. El fundamento basado en el monoteísmo que unía estas tres religiones abrahámicas, facilitó la interacción entre ellas. El Corán fue el libro sagrado que menos informaciones reveló sobre Eva. Por lo cual, exegetas, tradicionalistas y narradores buscaron detalles en las narraciones bíblicas y post-bíblicas. Así, se construyeron las leyendas progresivamente en unos entornos en plena efervescencia espiritual y cultural. De acuerdo con la tradición islámica, las leyendas de los personajes bíblicos empezaron a desarrollarse y a circular gracias a dos vías importantes: por una parte, los narradores o qușsāș. Por otra parte, los conversos del Cristianismo y del Judaísmo al Islam, que se consideraban como los mejores expertos en los relatos bíblicos. Se vivió una época evolutiva en las relaciones entre Islam y Judaísmo. Por lo cual, podemos considerar la leyenda de la tradición islámica como extensión del relato bíblico y podemos denominarla midrash islámico.

Un estudio cuidadoso del relato en ambas tradiciones nos reveló discrepancias esenciales. El Corán no hizo de Eva el punto de mira de la seducción satánica ya que no desempeñó el papel de intermediario nefasto como lo hizo en la Biblia. Eva no sedujo a Adán y no llevó el traje de tentadora como la Eva bíblica. El Corán acusó a Adán y a su mujer sin volcar la culpa sobre uno u otro, ya que cada uno será responsable de lo que haya cometido (Cor 74. 38). Sin embargo, la tradición islámica introdujo gracias a las referencias judeo-cristianas cambios significativos, y se alteró la imagen de Eva hasta convertirse en tentadora y pecadora. Esta imagen se desarrolló y dominó en las escrituras que siempre pusieron de relieve las deficiencias de la mujer.

Hombre y mujer han sido creados iguales, pero después, el hombre decidió tomar las riendas de la humanidad. Tomando el poder, impuso poco a poco su propia visión de la mujer. Empezó a colgarle la culpa del pecado en sus hombros. La hizo responsable del drama difundiendo estas ideas a través de sus escritos meramente elaborados por y para varones. Gradualmente, a través de las prácticas religiosas cada vez más estrictas, se introdujeron las en las interpretaciones de los textos sagrados, y llegó el hombre finalmente, a poner a la mujer en un escalón inferior al suyo, dejando crecer una brecha entre ellos. Las tradiciones judía e islámica ayudaron en la progresión de la desigualdad de los géneros. Las autoridades rabínicas y musulmanas excluyeron a la mujer de sus religiones para privilegiar celosamente sus propias relaciones con Dios.

A través de los personajes femeninos en los textos sagrados, se desencadenan acontecimientos que determinarán la historia masculina. Y es precisamente mediante

Ibn Katīr, 48.

Ibíd.; T̄a'labī, 38 . 
la imagen de Eva, con la que se establecen unas primeras pautas que adecuan el papel de las mujeres a los intereses teológicos y a la curiosidad humana.

\section{Bibliografía}

\subsection{Fuentes}

Ibn al-Ațīr, al Kämil fì al-tarīj I, Beirut, 1979.

Al-Kisā'̄ì, Qișas al-anbiyā', Chicago, 1997.

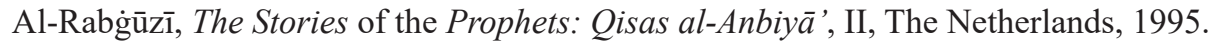

Tabarī, the Commentary on the Qur'an I, London, 1989.

Ta 'labī, Qisas al-anbiyā' al musammāt bi-l- 'arā'is, 1878.

Al-Zamajšarī, Al-fā 'iq fì garīb al-hadīz wa-l-āzāor, I, 1971².

\subsection{Literatura secundaria}

G. Anderson, Literature on Adam and Eve: Collected Essays, Boston, 2000.

J. Aronson, the Encyclopedia of Jewish Symbols, Oxford, 1992.

J. Baskin, Midrashic Women: Formation of the Feminine in Rabbinic Literature, London, 2002.

C. Castillo; M. Pérez, Tradiciones populares judías y musulmanas Adán, Abraham, Moisés, Navarra, 2009.

C. Castillo, «Aportación a la mítica historia de Adán y Eva (I),(II)», Miscelánea de Estudios Árabes y Hebraicos 29-30 (1980-1982) 35-52.

J. Coppens, La Connaissance du Bien et du Mal et le Péché du Paradis, Paris, 1948.

J. Decourdemanche, «La Légende d'Adam chez les Musulmans», Revue de l'Histoire des Religions, I, Paris, 1882.

R. Davidson, «The Theology of Sexuality in the Beginning: Genesis 1-2», Andrews University Seminary Studies 26 (1988) 5-21.

M. Faher, Critique des Représentation de l'Islam Contemporain, 2003.

L. Ginzberg, The Legends of the Jews, Vol. I: From the Creation to Jacob, Philadelphia, 1998.

C. Lévi-Strauss, Anthropologie Structurale, Paris, 1958.

D. Gondar, Estudio Exegético de Gn4. 1-16, Pamplona, 2010.

I. Gómez A., Un Jurado Femenino Declara a Eva no Culpable: Relectura del Génesis, Bilbao, 1997.

J. Hussain, Islam: Its Law and Society, Sidney, 2011.

R. Kimelman, «The Seduction of Eve and the Exegetical Politics of Gender», Woman of the Hebrew Bible, New York, (1999) 247-261.

K. Kvam, L. Schearing; L. Ziegler, Eve and Adam: Jewish, Christian, and Muslim Readings on Genesis and Gender, Indiana, 1999.

R. W. Moberly, «Did the Serpent Get it Right?» Jewish Theological Studies, 39 (1988) 1-27.

M. Navarro Puerto, «A imagen y semejanza divinas. Mujer y varón en Gn1-3 como sistema abierto», La Torah. Colección La Biblia y Las Mujeres, (2010) 209-262.

J. Ruiz Matorell, «Adán y Eva: El drama del Ser Humano», Personajes del Antiguo Testamento, Zaragoza, 1998.

D. Sidersky, Les Origines des Légendes Musulmanes dans le Coran et dans les vies des Prophètes, Paris, 1933. 